\title{
GENERAL
}

\section{THE COMPREHENSIBILITY OF LEAFLETS ATTACHED TO OTC ANALGESICS - PILOT SURVEY OF OPINIONS IN POLAND}

\author{
LUCYNA BUŁAŚ ${ }^{*}$, JUSTYNA HANSEL ${ }^{2}$, ANNA WAJDA², BARBARA DOLIŃSKA ${ }^{1}$ \\ and MARIOLA DROZD
}

\author{
${ }^{1}$ Department of Pharmaceutical Technology, Medical University of Silesia, Katowice, Poland \\ ${ }^{2}$ Science Club of Department of Pharmaceutical Technology, Medical University of Silesia, \\ Katowice, Poland \\ ${ }^{3}$ Department of Applied Pharmacy, Medical University of Lublin, Poland
}

\begin{abstract}
The aim of the study was to present the opinions on the leaflets attached to the packages of Over-thecounter (OTC) analgesics, taking into account the place of purchase and the usefulness of the information contained in the leaflet. The survey was conducted in Poland at the turn of February/March 2016 and June/July 2017. The authors constructed an original questionnaire consisting of 24 questions, both open and closed type. The survey was addressed to adults. In total 303 respondents were surveyed. Student t-test and Pearson's chisquared test were applied to determine differences between statistics, $\mathrm{p}<0.05$ was assumed as statistically significant. The respondents indicated a pharmacy as the main place of purchasing OTC analgesics. Most of the respondents declared that they read the leaflet attached to the package, and the font size used is large enough and legible. However, if it is difficult to read the information contained in it, and the majority of patients do not turn to the doctor or pharmacist for advice. The obtained results confirm that patients purchase and use drugs with increasing awareness. The study found that patients do not always understand drug information leaflets, and they do not always turn to professionals for counseling. The information contained in leaflets should be presented in a way that is clear, concise, and easily understandable to patients. It appears that the implementation of pharmaceutical care would greatly improve the safety of pharmacotherapy, including OTC non-steroidal anti-inflammatory drugs (NSAIDs).
\end{abstract}

Keywords: OTC analgesics, leaflet attached to the drugs, source of information about OTC drugs

Over-the-counter (OTC) analgesics consist of a low dosage of analgesic substances and don't require the doctor's prescription. They are taken by the whole community, often without insight into the risks associated with their misuse. (1). According to recent data, $89 \%$ of Poles purchase OTC drugs of which almost $70 \%$ are analgesics. These numbers range Poland in fifth place in Europe in terms of the frequency of buying painkillers (2). On the one hand, easy access to this group of drugs facilitates the reduction of pain. On the other hand, however, it contributes to negative consequences related to various adverse effects due to their misuse. Nowadays more and more health products became available without prescription. Data shows that over the counter drugs are more than $10 \%$ of whole pharmaceutical products and this number increases every year (3).
According to the World Health Organization (WHO), pain is 'an unpleasant sensory and emotional experience related to actual or potential tissue damage or described as such'. It should be noted that the feeling of pain is a subjective symptom that can be associated with any negative health condition, either mental or physical (4).

The largest group of OTCs taken to relieve pain are non-steroidal anti-inflammatory drugs (NSAIDs). Preparations from this group not only reduce or suppress pain, but also act as anti-inflammatory, anti-aggregating, and antipyretic agents. Commonly used NSAIDs are divided in terms of chemical structure. Most common are propionic acid derivatives such as ibuprofen, ketoprofen, naproxen, salicylates like acetylsalicylic acid, or paracetamol $(1,5)$.

\footnotetext{
* Corresponding author: e-mail: lbulas@sum.edu.pl
} 
The USA Food and Drug Administration (FDA) stated that accurate, thorough, and understandable information about drugs is necessary (6). Smith and Koehlmoos commented that 'high quality information is essential for good health, yet many individuals, practitioners, and health organizations, particularly in low- and middle-income countries lack information'. They also said that the lack of relevant reliable healthcare information should no longer be a major contributor to avoidable death and suffering (7).

The current Act of September 6 on Pharmaceutical Law in art. 2 para. 41 provides the following definition of medicine leaflet: 'the leaflet is information intended for the user, approved in the marketing authorization process, made in the form of a separate print, and attached to the medicinal product'(8). Safe use of medicines by patients requires a comprehensible message regarding basic information about the medicine being used. According to the binding directives in force from 1999, the leaflet for the patient must be enclosed in each package containing the drug, and its content must be in accordance with the 'Specification Sheet of the Medicinal Product'. In addition, it has to be consistent with the health-related outcomes, based on relevant, major clinical trials. The information contained therein should be understandable, useful, and short, presented in aesthetic form $(9,10)$.

For the sake of clarity, the leaflet content should be divided thematically into the following parts:

- What a_medicine $\mathrm{X}$ is, and what it is used for?

- Important information before using medicine X.

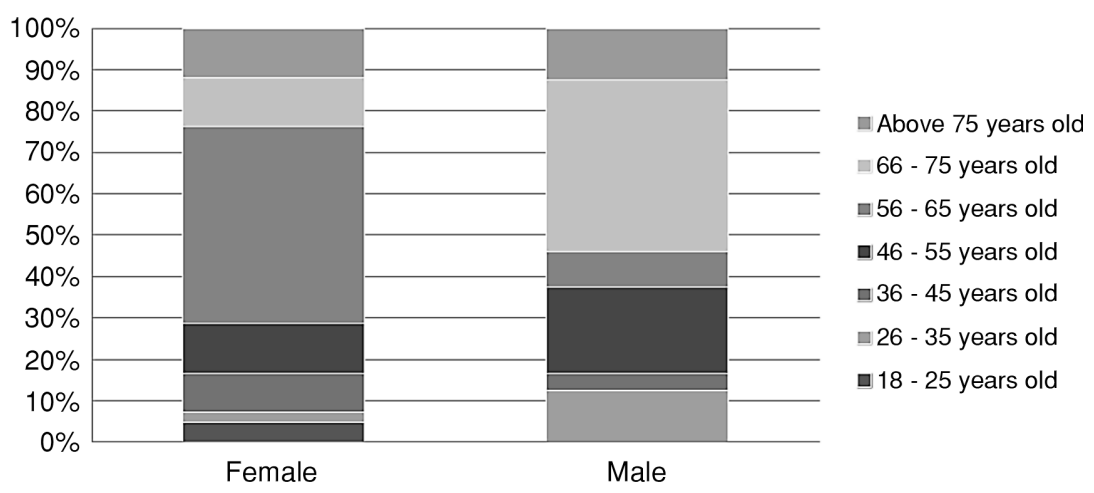

Figure 1. The distribution of answers to the question: "Do you have an OTC analgesic with you?"

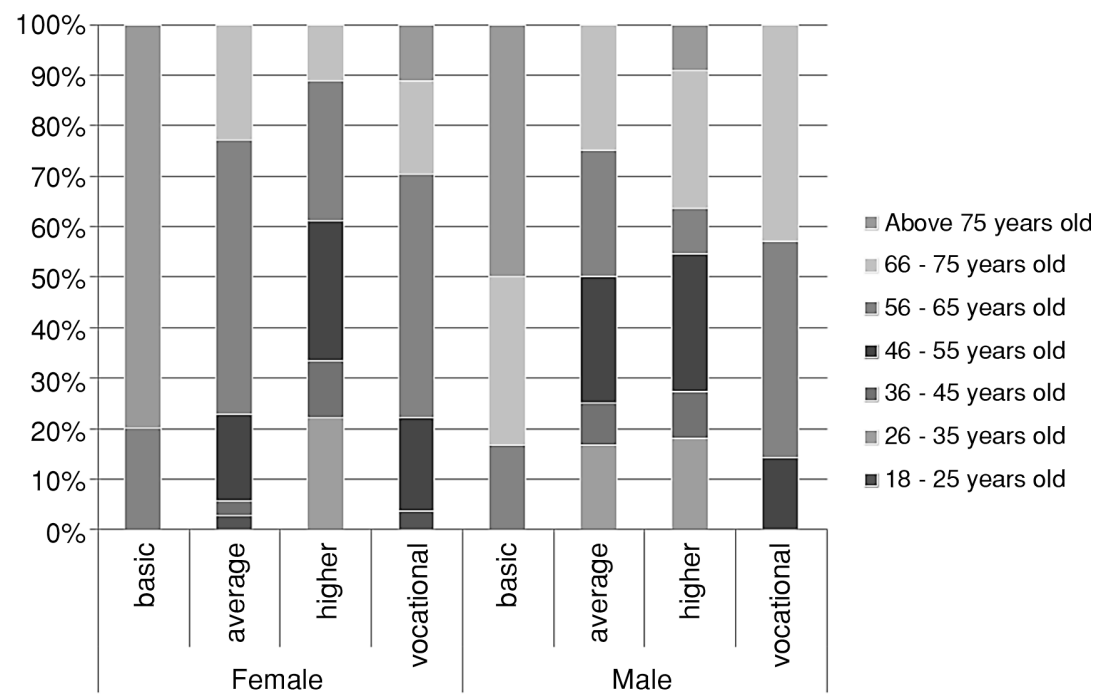

Figure 2. Age distribution of respondents who think that OTC analgesics are safe. 
- How to use medicine X.

- Possible side effects.

- How to store medicine X.

- Package contents and other information (11). Such division of leaflet content should ensure easy access to necessary information when using the drug. Most of the leaflets that are enclosed with OTC medicines also contain the introductory information that 'One should read the leaflet carefully before using the medicine as it contains information important for the patient'. The manufacturer clearly indicates that the medicine should always be taken exactly as directed in the enclosed leaflet. Another method of dosing provides for consultation and taking the medicine 'as prescribed by the doctor or recommended by the pharmacist'. It is also suggested the patient should keep the leaflet to be able to read it again (12).

\section{Objective}

The aim of this study was to learn the respondents' opinions on the leaflets attached to OTC analgesics, including the assessment of the information usefulness, relevant to the drug use (e.g., with some other agents or food), font size, text composition, and possible difficulties with reading, understanding or interpreting of the contents).

\section{Methods}

The authors constructed an original questionnaire consisting of 24 questions, both open and closed type, that were addressed to students of major universities in Poland. The electronic form of the questionnaire was placed on a social networking site. After a preliminary analysis of the results, the respondent group was extended to include other adults with different educational and professional status. Then a paper form of the questionnaire was prepared. The survey was conducted at the turn of February/March 2016 and June/July 2017. In total, 303 respondents participated, and 155 electronic forms and 148 paper forms of the questionnaire were collected. The respondents were informed about the anonymity of the survey.

Descriptive statistics in the form of frequency distributions and percentages were obtained for each of the examined parameters. Statistical analysis was performed in the STATISTICA 12 program. Student t-test and Pearson's chi-squared test were applied to determine differences between statistics, and $\mathrm{p}<0.05$ was assumed as statistically significant.

\section{RESULTS}

The questionnaire focused on the comprehensibility of the leaflets attached to OTC analgesic pack- ages. The characteristics of the study group are presented in Table 1 . The majority of respondents were women $(69.3 \%)$.

To characterize the study group, the respondents were subdivided according to age, occupational status, and education. The most numerous group were people aged between 18 and 25 (76 respondents). The second largest group were people aged 56-65 (60 respondents). The majority of respondents declared that they are professionally active (47.2\%), $26.4 \%$ reported they are already retired, and as many as $42.9 \%$ of respondents had secondary education.

The study of leaflet's readability and comprehension by patients is a particularly important issue, especially as the number of OTC users has been increasing. The study found that OTC analgesics are taken by a large majority of the respondents, most frequently by women aged 56-65, and considerably less frequently by men, often aged 66-75. The above results are presented in Figure 1. Statistically, the age of OTC analgesics users correlated with gender $(p=0.005)$.

Nearly half of the respondents, in particular people aged 56-65 think that NSAIDs are safe drugs (Fig. 2). Statistical analysis of females' responses revealed dependence at $\mathrm{p}=0.001$, however, it found no correlation in the group of male respondents $(\mathrm{p}=0.514)$.

The results also found that pharmacy is the main place where OTC analgesics are purchased. The second frequently visited place to buy OTC analgesics is a local shop. The results are shown in Table 1 . In the case of females, statistical analysis showed that the tested characteristic is independent ( $p=0.033$ ), while for males this hypothesis should be rejected $(\mathrm{p}=0.057)$.

As many as $81 \%$ of respondents declared that they read the leaflet enclosed in the medicine packaging. Statistical analysis revealed a correlation between reading the leaflet and age $(\mathrm{p}=0.014)$, while the analysis in terms of education showed no dependence $(\mathrm{p}=0.212)$. The majority of this group were females, and mostly 18-25 - year old (20.1\%). The next in terms of population size are respondents aged 56-65. The answers given by men and women of all ages are presented in Figures 3. The analysis of the obtained data indicates that the most frequently read leaflet sections are: 'how to use the medicine', 'what is medicine $\mathrm{X}$ and for what purpose it is used'. As the main reason for not reading the leaflet, the respondents indicated the lack of time. Those patients prefer to seek advice from the pharmacy where they buy the medicine.

The respondents aged 18-25 found that the font size in the leaflets was insufficient. Interestingly, 56-65 - year old respondents did not report this 
inconvenience. This applies to both females and males (Fig. 4). Statistical dependence between the font size in leaflet and age was found $(p=0.005)$.

Those respondents more often asked medical professionals about possible interactions of OTC NSAIDs with other medicines (Table 1). Information on OTC analgesics was obtained by $47 \%$ of respondents from a pharmacists, and only $17 \%$ from a physicians. About $30 \%$ of respondents declared that they gained their knowledge on medicaments from the Internet, television or newspapers.

Despite the difficulties in reading and interpreting the content of the leaflet, as many as $57 \%$ of respondents did not seek the help of a doctor or pharmacist.

\section{DISCUSSION}

The pain (e.g., chronic type of pain) has many negative consequences, and as such, it needs to be alleviated. However, it is also a warning signal (e.g., an acute type of pain) of some harmful agents (e.g., mechanical, chemical or thermal factors) that can threaten the body. It should also be noted that chronic pain may be associated with gloom, extreme fatigue and depression, and may also lead to suicide attempts (13).

This fact may explain the growing interest in analgesics, among many patients, who are constantly exposed to numerous OTC pharmaceutical products, aggressively advertised on the market. In addi-

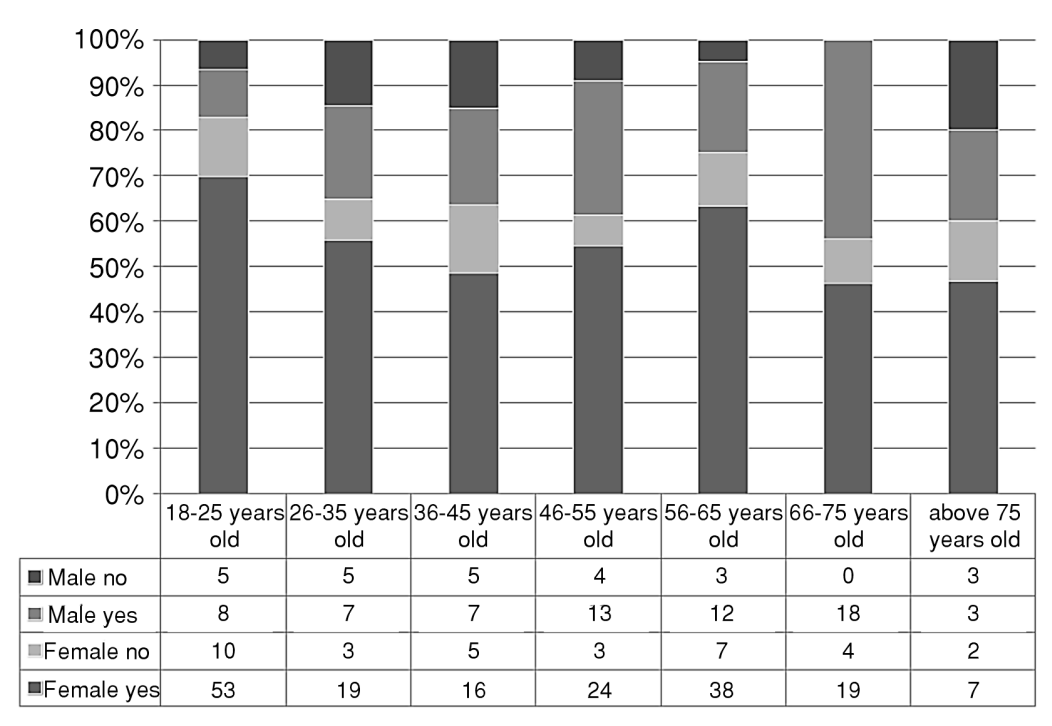

igure 3. Men and women responses to: "Do you read the leaflet attached to the packaging?"

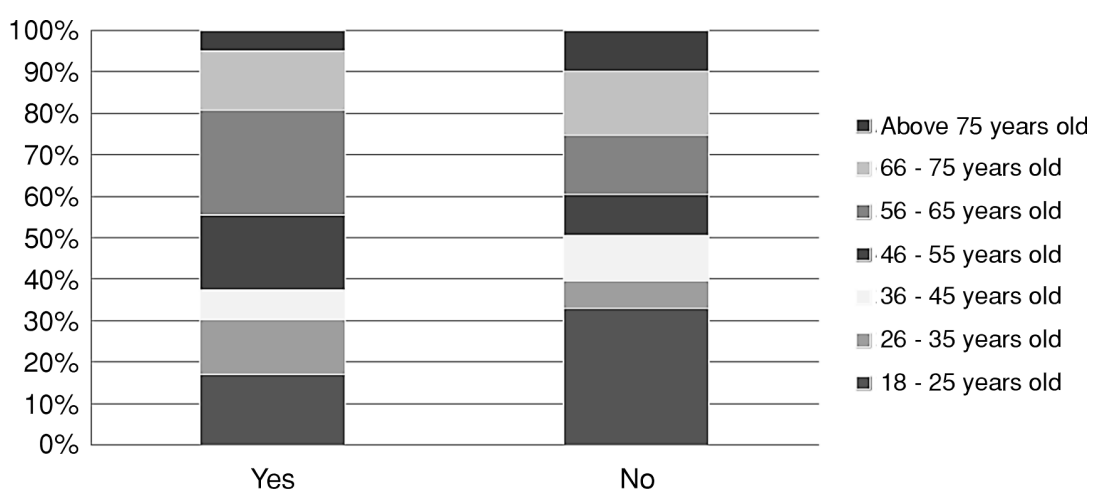

Figure 4. Respondents' answers to the question: "Do you think that the font size used in leaflets of OTC analgetics is large enough and legible?" 
Table1. Characteristics of the respondents $(n=303)$.

\begin{tabular}{|c|c|c|c|c|}
\hline \multirow{2}{*}{\multicolumn{3}{|c|}{$\operatorname{Sex}(n=303)$}} & \multirow{2}{*}{$\begin{array}{c}\text { Female } \\
210(69.3 \%)\end{array}$} & \multirow{2}{*}{$\begin{array}{c}\text { Male } \\
93(30.7 \%)\end{array}$} \\
\hline & & & & \\
\hline \multirow{7}{*}{ Age in years $(n=303)$} & \multicolumn{2}{|c|}{$18-25$} & $63(22.8 \%)$ & $13(4.3 \%)$ \\
\hline & \multicolumn{2}{|l|}{$26-35$} & $22(7.3 \%)$ & $12(4 \%)$ \\
\hline & \multicolumn{2}{|c|}{$36-45$} & $21(6.9 \%)$ & $12(4 \%)$ \\
\hline & \multicolumn{2}{|l|}{$46-55$} & $27(8.9 \%)$ & $17(5.6 \%)$ \\
\hline & \multicolumn{2}{|l|}{$56-65$} & $45(14.9 \%)$ & $15(5 \%)$ \\
\hline & \multicolumn{2}{|l|}{$66-75$} & $23(7.6 \%)$ & $18(5.9 \%)$ \\
\hline & \multicolumn{2}{|c|}{ Above 75} & $9(3 \%)$ & $6(2 \%)$ \\
\hline \multirow{4}{*}{ Education $(n=303)$} & \multicolumn{2}{|c|}{ Basic } & \multicolumn{2}{|c|}{$13(4.3 \%)$} \\
\hline & \multicolumn{2}{|c|}{ Vocational } & \multicolumn{2}{|c|}{$130(42.9 \%)$} \\
\hline & \multicolumn{2}{|c|}{ Average } & \multicolumn{2}{|c|}{$100(33 \%)$} \\
\hline & \multicolumn{2}{|c|}{ Higher } & \multicolumn{2}{|c|}{$60(19.8 \%)$} \\
\hline \multirow{6}{*}{ Occupational status } & \multicolumn{2}{|c|}{ Profesional active } & \multicolumn{2}{|c|}{$143(47.2 \%)$} \\
\hline & \multicolumn{2}{|c|}{ Annuitant } & & \\
\hline & Pension & & & $\%)$ \\
\hline & Unemplo & & & \\
\hline & Student of a medic & Iniversity & & $\%)$ \\
\hline & Non-medical coll & student & & $\%)$ \\
\hline & Physicia & & & $\%)$ \\
\hline & Pharmac & & & $9 \%)$ \\
\hline Source of knowledge & Interne & & & $\%)$ \\
\hline about OTC analgesics & $\mathrm{TV}$ & & & $\%)$ \\
\hline & Newspap & & & \\
\hline & Other pati & & & \\
\hline & & $18-25$ & $59(21.6 \%)$ & $13(11.6 \%)$ \\
\hline & Pharmacy & $26-35$ & $22(8.1 \%)$ & $11(9.8 \%)$ \\
\hline & (Female - 211 & $36-45$ & $20(7.3 \%)$ & $11(9.8 \%)$ \\
\hline & answers, Male - & $46-55$ & $25(9.2 \%)$ & $14(12.5 \%)$ \\
\hline & 86 answers) & $56-65$ & $39(14.3 \%)$ & $14(12.5 \%)$ \\
\hline & & $66-75$ & $20(7.3 \%)$ & $17(15.2 \%)$ \\
\hline & & Above 75 & $9(3.3 \%)$ & $6(5.4 \%)$ \\
\hline & & $18-25$ & $17(6.2 \%)$ & $1(0.9 \%)$ \\
\hline & & $26-35$ & $4(1.5 \%)$ & $6(5.4 \%)$ \\
\hline Place of purchase & Estate shop & $36-45$ & 0 & $2(1.8 \%)$ \\
\hline of OTC analgesics & (Female - 36 & $46-55$ & $4(1.5 \%)$ & $2(1.8 \%)$ \\
\hline (Female - 273 answers, & answers, Male - & $56-65$ & $7(2.6 \%)$ & $1(0.9 \%)$ \\
\hline Male - 112 answers) & 13 answers) & $66-75$ & $4(1.5 \%)$ & $1(0.9 \%)$ \\
\hline & & Above 75 & 0 & 0 \\
\hline & & $18-25$ & $21(7.7 \%)$ & $3(2.7 \%)$ \\
\hline & Hipermarket & $26-35$ & $6(2.2 \%)$ & $3(2.7 \%)$ \\
\hline & (Female - 39 answers, & $36-45$ & $4(1.5 \%)$ & $1(0.9 \%)$ \\
\hline & Male - 9 answers) & $46-55$ & $2(0.7 \%)$ & 0 \\
\hline & & $56-65$ & $3(1.1 \%)$ & $2(1.8 \%)$ \\
\hline & & $66-75$ & 0 & 0 \\
\hline & & Above 75 & 0 & 0 \\
\hline
\end{tabular}


Table1. Continued.

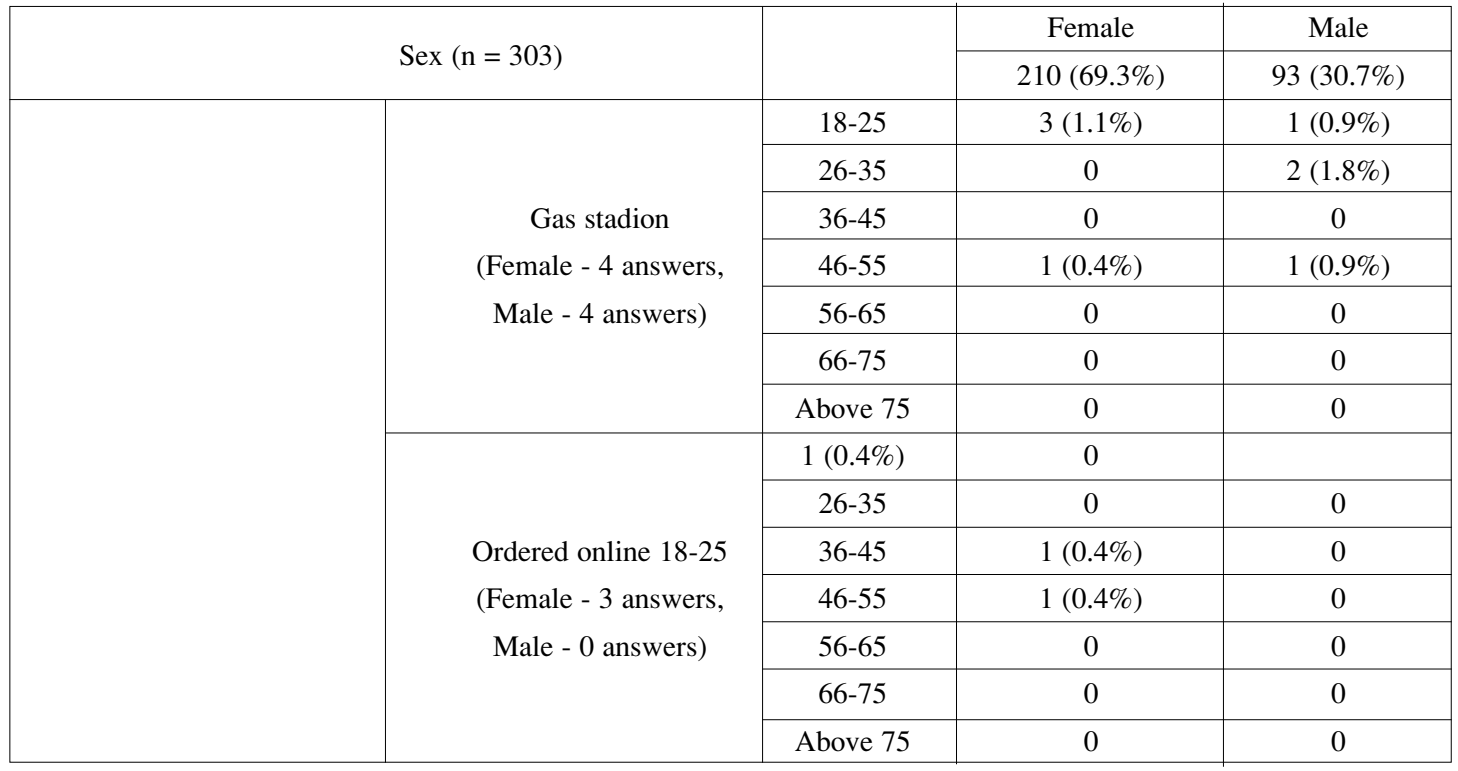

tion, the circumstances such as long waiting time for a medical appointment or the search for quick and easy solutions to health problems make patients more and more prone to reach out for medicines that do not require the doctor's prescription. Thus, it is extremely important that the leaflet included in the medicine package is understandable and legible to patients to ensure the highest possible effectiveness and safety of the medicines used.

In the Regulation of February 20, 2009, the Minister of Health defines the requirements for packaging as well as leaflets. It says that the leaflet content should be formulated according to the Characteristics of the Medicinal Product, and specifies the size and type of the font used. The most important postulate of the regulation is that the content should be comprehensible and clear. Before the medicinal product is authorized for sale, the manufacturer must carry out a readability test of the leaflet attached to the package (9).

The results by Sukkari et al. are consistent with other quality content studies of commercially available drug information leaflets for patients. They believe that developing countries often import drugs from many other countries. The information on the medical product varies in content (14). The study of the leaflet in terms of its readability and understandability by patients is of particular importance, especially because of the increasing number of people using OTC medicines. Therefore the native language used in the leaflets should follow the Keystone Criteria as the standard for medicine infor- mation. Keystone Criteria is subjective assessment developed by the strategy and economics consulting firm. These criteria include usability, functionality and attractiveness. According to "Keystone Strategy", attractiveness depends on six groups of factors: knowledge, efficiency, usability, flexibility, access to detailed data and cooperation. In clinical grading system, Keystone criteria are based on three standards: review, determine and develop. (15-17). Since November 1, 2005, testing the readability of leaflet content has been mandatory in all European Union countries. The relevant directive specifies that the text contained in the leaflet should be clear and understandable. The purpose of the leaflet readability test is to determine patient's ability to find and understand the information sought and to follow the issued recommendations. The content of the leaflet should be formulated after consultation with the target groups of patients, and the results presented by the manufacturer in the registration process (18).

The Scientific Institute of German Health Assurance conducted a study analyzing the leaflet content of 100 most frequently prescribed medications. The analysis showed that over $50 \%$ of the text was printed in smaller font size than recommended. Only 7 leaflets had numbered sub-items and a table of contents. Unfortunately, as many as 29 leaflets contained foreign phrases used without further explanation (19).

The study by Marfo et al. evaluated the quality of labeling of medicines and assessed patients' knowledge of the administration of medicines dis- 
pensed from a community pharmacy in Ghana. They found patients' knowledge about the administration of medicines above average, however requiring improvement (20). Our study confirms these results. Buying medicines without consulting the doctor or pharmacist requires a thorough understanding of the information provided by the manufacturer in the leaflet. In general, patients believe that the leaflet is directed to a person with medical education, because it contains many professional terms, and the font is too small. The drug itself, due to the fact that it is a non-prescription one, is considered as 'safe' medicine (11). However, in 2015 the Office for Registration of Medicines and Medicinal Products registered 117 cases of severe poisonings with OTC analgesics. These data do not reflect the entire scale of the problem. It is probably greater because the majority of complications are not reported to the appropriate institutions dealing with this problem (4).

In the study of Gibson et al. emphasizes that reading the leaflet may generate new patient knowledge about medicines and may have a positive impact on their behavior (21).

Hammar et al. examined patients' use and perception of the information leaflet enclosed in the medication package, and their attitude towards a transition to its electronic version. The study showed that $52 \%$ of the respondents occasionally read the leaflet, $37 \%$ always read it, and $11 \%$ never read it. Almost half of the patients were positive towards reading the electronic version of the leaflet (22).

Medicinal products containing active substances with analgesic activity can be obtained without prescription in a non-pharmacy sale, too. Specified package-sizes are available, among others, from general grocery stores and gas stations.

It is a standard practice that not only the leaflet but also every advertisement contains a recommendation that in case one needs advice or additional information, they should consult the doctor or pharmacist. Also, if any side effects have developed, including those not listed in the leaflet, the patient should inform the doctor or pharmacist.

\section{CONCLUSIONS}

Our research findings can be summarized into 5 key conclusions:

1. The vast majority of respondents use OTC analgesic medications.

2. The users are not always aware of the dangers of OTC medicines, considering them as safe. It rais- es concern, especially in the group of the elderly who suffer from many cardiovascular diseases, such as atherosclerosis or hypertension.

3. Pharmacy is the main place where OTC analgesics are purchased.

4. The problem with the font size in the leaflets of medicines was insufficient was most common among the people aged 18-25.

5. Although many patients often have problems with reading and interpreting the content of leaflets enclosed in the medicine packaging, they do not always turn to professionals for help. Therefore, it is essential that the leaflet information is presented in a way that is clear, concise, and easily understandable to patients.

It can be expected that the introduction of pharmaceutical care services into Polish pharmacies would greatly improve the safety of pharmacotherapy, including OTC NSAIDs.

\section{Conflict of interest}

The authors declare no conflicts of interest.

\section{REFERENCES}

1. Weiner M., Tokarska-Rodak M., Bida A.: Rozprawy Społeczne 13, 72 (2019), (in Polish).

2. Feliksiak M.: Komunikat z badań nr. 158/2016. (2016), ( in Polish). CBOS. Available in: https://cbos.pl/SPISKOM.POL/2016/K_158_1 6.PDF.

3. Sadak G.: OTC review. (2018). Available in: https://www.iqvia.com/pl-pl/blogs/2018/04/ otc-review-2018.

4. Dobrogowski J., Zajączkowska R., Dutka J., Wordliczek J.: Pol. Prz. Neurol. 7, 20 (2011), (in Polish).

5. Wójcik-Jawień M., Sokal M.: Farm. Pol. 7, 291 (2008), (in Polish).

6. Department of Health and Human Services. Food and Drug Administration. Prescription Drug Product Labeling; Medication Guide Requirements 60, 44182 (1995).

7. Smith R., Koehlmoos T.P.: BMJ 342, d4151 (2011).

8. The Act of September 6, 2001 Pharmaceutical law Article 2, paragraph 41. Dz. U. 2001 No. 126 poz. 1381 (in Polish).

9. Ślęczek-Czakon D.: Zeszyty naukowe Politechniki Śląskiej 1996, 609 (2018), (in Polish).

10. Guidelines of the European Commission regarding the information requirements on the 
packaging and leaflets placed inside the package art. 56a, Directive 2004/27/EC. Available at: http://pzn.org.pl/wytyczne-komisji-europejskiej-dotyczace-wymagan-w-zakresie-informacji-na-opakowaniu-oraz-ulotki-umieszczonej-wewnatrz-opakowania-art-56a-dyrektywa-200427ec-braille. Accessed January 21, 2019 (in Polish).

11. Skowron A., Dymek J., Drozd M.: Farm. Pol. 8, 487 (2011), (in Polish).

12. Zieliński W.: The information leaflets and study of their readability. AWAFARM (2017), (in Polish).

13. Regulation of the Health Minister of November 21, 2008 on the advertising of medical products. Dz.U. 2008. No. 210 poz. 1327, (in Polish).

14. Sukkari S.R., Al Humaidan A.S., Sasich L.D.: Saudi Pharma. J. 20, 211 (2012), doi:10.1016/j. jsps.2012.01.006.

15. Rogalski M., Niedźwiedziński M.: Polskie Stowarzyszenie Zarządzania Wiedzą. Seria: Studia i Materiały 29, 125 (2010), (in Polish).
16. Qian L., Wu Z., Shen J.: J. Cell Mol. Med. 17, 966 (2013).

17. Keystone. Available at: https://www.keystonestrategy.com/about-keystone/. Accessed October 4, 2019.

18. Directive 2004/27 / EC of the European Parliament and of the Council of 31 March 2004 amending Directive 2001/83 / EC on the Community code relating to medicinal products for human use.

19. Kocot-Kępska M., Dobrogowski J.: The types of pain. In: Neurology, regional anasthesia and therapy of pain. Andres A., Dobrogowski J., pp. 239-253, CEEA-Ośrodek Regionalny, Kraków, 2011 (in Polish).

20. Marfo A.F., Owusu-Daaku F.T., KyerewaaAkromah E.: Pharm. Pract. 11, 66 (2013).

21. Gibson Smith K., Booth J.L., Stewart D., Pfleger S., McIver L., MacLure K.: Pharm. Pract. 15, 1082 (2017).

22. Hammar T., Nilsson A.L., Hovstadius B.: Pharm. Pract. 14, 702 (2016). 